\title{
Synthesis, Characterization and Adsorption of Bisphenol A Using Novel Hybrid Materiel Produced from PANI Matrix Reinforced by Kieselguhr
}

\section{Dalila Ouis}

University of Mustapha Stambouli Mascara

Abdelkader El Kebir

University Mustapha Stambouli of Mascara

Imane Moulefera

University of Mustapha Stambouli Mascara

Lilia Sabantina

Bielefeld University of Applied Sciences

Benyoucef Abdelghani ( $\square$ abdelghani@ua.es )

University of Mustapha Stambouli Mascara https://orcid.org/0000-0002-0247-2808

\section{Research Article}

Keywords: PANI, Kieselguhr, Hybrid material, Adsorption, Bisphenol A.

Posted Date: November 8th, 2021

DOI: https://doi.org/10.21203/rs.3.rs-1036863/v1

License: (c) (i) This work is licensed under a Creative Commons Attribution 4.0 International License.

Read Full License

Version of Record: A version of this preprint was published at Journal of Inorganic and Organometallic Polymers and Materials on November 13th, 2021. See the published version at https://doi.org/10.1007/s10904-021-02151-6. 
1 Synthesis, characterization and adsorption of Bisphenol A using novel hybrid materiel produced from PANI matrix reinforced by Kieselguhr Abdelghani ${ }^{1 *}$

6

${ }^{2}$ Department of Electrical engineering, University Mustapha Stambouli of Mascara, 29000;

9 Algeria.

${ }^{3}$ Departamento de Ingeniería Química, Universidad de Málaga, Andalucía T.E.C.H, Málaga, Spain.

${ }^{4}$ Junior Research Group “Nanomaterials”, Faculty of Engineering and Mathematics, Bielefeld University of Applied Sciences, 33619 Bielefeld, Germany; (L.S.) 


\section{Abstract}

This study investigated the preparation of new adsorbent based PANI and Kieselguhr (KG). The produced materials were characterized by XRD, XPS, TEM, FTIR, TGA and BET. Thereby, hybrid material PANI@KG highest $\mathrm{S}_{\mathrm{BET}}$ values (about $47.82 \mathrm{~m}^{2} \cdot \mathrm{g}^{-1}$ ). The adsorption capacity of the PANI, KG and PANI@KG were tested on BPA ions from aqueous solutions at ambient temperature and $\mathrm{pH}$ 6.0, the maximum capacity of adsorption was observed to be $63.68 \mathrm{mg} \cdot \mathrm{g}^{-1}$ which is obtained from Langmuir adsorption isotherm by hybrid adsorbent PANI@KG. Besides, the pseudo-2nd order kinetics was more consistent with the obtained experimental data. Furthermore, the hybrid material possessed highest adsorption capacity after six cycles of adsorption-desorption process. Moreover above $80 \%$ of removal percentage was obtained even after three recycles. Hence we expect that this organic-inorganic adsorbent can be selected as a potential candidate for water treatment.

7 Keywords: PANI; Kieselguhr; Hybrid material; Adsorption; Bisphenol A. 


\section{Introduction}

Certain phenolic components are some of the most contaminating and serious organic chemicals even at their low concentration for the destroyed effect against human health [1]. So the elimination of those products from wastewater is defiance for researchers. Among all, Bisphenol A (BPA), one of phenolic materials consisting two aromatic rings and two hydroxyl groups, is applied in the production of epoxy resin and polycarbonate $[2,3]$, and can also be applied as an additive in flame retardants, plasticizers, antioxidants, etc. [4, 5]. Moreover, BPA is acceptably soluble in water at $298 \mathrm{~K}$, and its occurrence in water come mainly from chemical industrials activity and wastewater treatment facilities $[6,7]$. Thus, developing of novel ways for efficient removal of BPA from the aqueous solution is highly desirable, e.g. oxidation method [8], electrochemical oxidation [9], membrane filtration [10], reverse osmosis [11], chemical coagulation [12], photocatalysis [13], biological methods [14], adsorption method [1, 3], etc, in which the adsorption is the simple and most effective.

Kieselguhr $(\mathrm{KG})$ or diatomaceous earth is categorized as non-crystalline conforming to the mineralogical class. $\mathrm{KG}$ usually consists about $90 \% \mathrm{SiO}_{2}$, with significant quantity of $\mathrm{Al}_{2} \mathrm{O}_{3}$ and $\mathrm{Fe}_{2} \mathrm{O}_{3}$ and some other impurity. $\mathrm{KG}$ can be facilely produced at a low cost because diatomaceous silica is the most abundant form of silica on the earth [15-18]. Highly sorption ability, perfect porous structure, chemical stability, accepted surface area, low density are some unique proprieties of KG [19]. Due to these exceptional characteristics KG be used in many several applications such as adsorbent, filter aid, catalyst supports or carrier, insulating materials, natural insecticides, and etc [20, 21]. 
Among the conducting polymers, PANI is one of the most popular due to its simple preparation, high redox stability, and high capacitance, low cost and eco-friendly performance [22-25]. It is selected as an active material from the viewpoint of technological applicationoriented and scientific research, owing to its ease of synthesis, wide variety, and efficiency [25, 26]. It has been described that it is exceedingly employed in combination with hybrid materials to ameliorate properties, such as PANI/Diatomite [27], Fibrillar polyaniline/diatomite [28], PANI-doped tin oxide-diatomite [29] and mDE@PANI [30].

The particular of our present work is that a adsorbent PANI@KG was prepared through polymerization of aniline in the dispersed system of $\mathrm{KG}$, and was characterized via different ways, including XPS, FT-IR, XRD, TGA, TEM and BET. The adsorption kinetics and equilibrium isotherms for BPA removal has been examined with variation in process parameters, e.g. BPA concentration, Influence of $\mathrm{pH}$, contact time, isotherm and regeneration.

\section{Experimental}

\subsection{Materials}

Aniline (ANI) (Aldrich, $\geq 99.5 \%$ purity), Bisphenol A (BPA) (Aldrich, $\geq 99 \%$ purity), Kieselguhr (KG) (ENOF, Algeria), Ammonium persulfate (APS) (Merck, $\geq 98 \%$ purity), Ammonia solution $\left(\mathrm{NH}_{4} \mathrm{OH}\right)$ (Merck, $25 \%$ purity), Perchloric acid $\left(\mathrm{HClO}_{4}\right.$, Merck, $70 \%$ purity), Hydrochloric acid ( $\mathrm{HCl}$, Merck, 37\%), Ethanol $\left(\mathrm{C}_{2} \mathrm{H}_{5} \mathrm{OH}\right)$ (Merck, 96\% purity) and the ultrapure $\mathrm{H}_{2} \mathrm{O}$ (18.2 M $\left.\mathrm{M.cm}\right)$ employed in all experiments were obtained from an ElgaLabwater-Purelab system.

\subsection{Measurements}



3000Electron). X-ray diffraction patterns of all the samples were attained on Bruker-CCDApex instrument in $2 \theta$ range of $0.2^{\circ}-70^{\circ}$ at a scan rate of $10^{\circ} \mathrm{min}^{-1}$ using $\mathrm{Cu}-\mathrm{K}_{\alpha} \mathrm{X}$-ray radiation source. Fourier transform infrared spectrum (FTIR) was carried out by Bruker-Inc., Model-Alpha spectrometer between $400-4000 \mathrm{~cm}^{-1}$. The morphologies on their surface were investigated by using transmission electron microscopy (TEM) (JEOL-JEM-2010). UV-Vis spectra (Hitachi_U3000-Spectrophotometer) were tested to calculate the BPA concentrations. Thermogravimetric analysis (TGA) (Hitachi-STA 7200Instrument) was applied to define the thermal stability of adsorbents. The BET isotherms of the materials were obtained from a Autosorb-6-Quantachrome system at liquid $\mathrm{N}_{2}$ temperature $(77 \mathrm{~K})$. Correspondingly, $\mathrm{N} 2$ adsorption is fundamentally to gain the data on total micropore volume $\left(\mathrm{V}_{\mathrm{DR}}\right)$ using the Dubinin Radushkevich (DR) law and to calculate the specific surface area according to BET equation $\left(\mathrm{S}_{\mathrm{BET}}\right)[21,22]$.

\subsection{Adsorbents preparation}

Solutions were prepared by adding $10 \mathrm{~g}$ of $\mathrm{KG}$ compound to $500 \mathrm{ml}$ of $\mathrm{HCl}(1 \mathrm{M})$ followed by continuous stirring for $1 / 2 \mathrm{~h}$. About $1.35 \mathrm{~g}$ of ANI was then added to each previous solution with continuous stirring for $24 \mathrm{~h}$. The polymerization process is carried out at room temperature by APS as oxidizing agent (applied 1:1 APS/ANI mole ratio) following the reported procedure [28-32]. The obtained PANI@KG material were vacuum dried at $65^{\circ} \mathrm{C}$ for $4 \mathrm{~h}$ to be ready for further characterizations. The PANI was prepared in same method abovementioned but in without presence of KG.

\subsection{Batch adsorption experiments for removal of BPA}



the synthesized materials. A known amount of adsorbent along with $25 \mathrm{~mL}$ of test solution containing BPA were taken in pyrex bottles and agitated in an orbital shaker for 4 hours to reach equilibrium. After agitation, the absorbent was removed and the concentration of BPA in the filtrate was analyzed using UV-vis.

On account of finding the adsorption capacity of the adsorbent, the uptake of BPA by unit gram of adsorbent is calculated using the following equation [31],

$$
Q_{e q}=\frac{\left(C_{0}-C_{e q}\right) V}{m}
$$

where $C_{0}$ is the initial BPA concentration and $C_{e q}$ represents the equilibrium concentration of BPA, $Q_{e q}\left(\mathrm{mg} \cdot \mathrm{g}^{-1}\right)$ denotes the adsorption capacity, $V$ being the volume of BPA solution $(L)$, and $\mathrm{m}$ indicates the adsorbent dosage $(g)$.

\section{Results and Discussion}

\subsection{Physicochemical characterization}

XPS was carried out to further analyze the chemical composition of the synthetized materials. Fig. 1-a. show the XPS wide survey spectrum of KG material give the characteristic peaks of Si2p3, Si2p1, Ca2p3, Ca2p1, Fe2p and O1s with the assigned binding energies of $102.70 \mathrm{eV}, 103.43 \mathrm{eV}, 347.82 \mathrm{eV}, 350.95 \mathrm{eV}, 710.59 \mathrm{eV}$ and $531 \mathrm{eV}$, respectively. Furthermore, the binding energy values of the principal peaks (Si2p, O1s, C1s and N1s) in the investigated PANI@KG are reported in Table 1, and Cl1s peak at 200.15 eV displays the presence of chlorine $(\mathrm{Cl})$. The $\mathrm{Cl}$ peak exhibits that $\mathrm{HClO}_{4}$ added over at synthesis reaction, together with the signals of $\mathrm{C}$ and $\mathrm{N}$ elements can be clearly observed in PANI chain. 
Fig. 2-a. displays the high resolution C1s spectra of PANI. We can see that four kinds of peaks centered at $284.56 \mathrm{eV}(\mathrm{C}-\mathrm{H} / \mathrm{C}-\mathrm{C} / \mathrm{C}=\mathrm{C}), 285.66 \mathrm{eV}(\mathrm{C}-\mathrm{O}), 286.94 \mathrm{eV}(\mathrm{C}-\mathrm{O})$ and 290.96 $\mathrm{eV}(\mathrm{O}-\mathrm{C}=\mathrm{O})$. These functional groups mentioned are in approval with other work. [21, 22]. Similarly, the same peaks attributed to PANI were displayed in the C1s spectrum of PANI@KG and the content of the $\mathrm{O}-\mathrm{C}=\mathrm{O}$ group were disappeared (Fig. 2-b), supporting the reaction between PANI and KG. The high-resolution XPS spectra are summarized in Table 1. Moreover, The N1s spectra of PANI consist of three broad peaks, at $399.45 \mathrm{eV}, 400.62 \mathrm{eV}$ and $401.83 \mathrm{eV}$ shows the presence of quinoid phenyl structure $(-\mathrm{N}=)$, benzenoid structure $(-\mathrm{NH}-)$ and quaternary ammonium salt structure $\left(\mathrm{N}^{+}\right)$, respectively. Likewise, after the deconvolution, N1s of PANI@KG presents three peaks at $399.47 \mathrm{eV}, 400.68 \mathrm{eV}$ and $402.16 \mathrm{eV}$ assigned to $(-\mathrm{N}=),\left(-\mathrm{NH}^{-}\right)$and $(\mathrm{N}+)$ respectively, as exhibit in Fig. 2-(c,d). It may be mentioned that N1s spectra is moved to higher binding energies value indicating the modification electronic charge of nitrogen.

In Fig. 1-b. the XRD pattern reveals the presence of an amorphous phase (opaline silica, $\mathrm{SiO}_{2} \cdot \mathrm{nH}_{2} \mathrm{O}$ ) with the characteristic broad peak centered at $22.62^{\circ}$, and a single sharp peak at $2 \theta$ $=26.26^{\circ}$ corresponding to amorphous $\mathrm{SiO}_{2}$ with small amount of quartz [32]. Moreover, the amorphous character of pure PANI is indicated by the hump-like peak at $2 \theta$ range $10-35^{\circ}$ [33]. The XRD pattern of PANI@KG revealed mixed phases, it because a change in their peak positions and shapes compared with the pure PANI and KG indicating that either the KG was successfully incorporated into the PANI matrix or the KG were dispersed well on the surface of the PANI chain.

FTIR spectroscopy was carried out to analyze the surface characteristics of PANI, KG and PANI@KG samples. In Fig. 3. the spectrum of $\mathrm{KG}$ confirms the presence of $\mathrm{CO}_{3}{ }^{2-}$ 
deformation bands at $1441 \mathrm{~cm}^{-1}$ and $870 \mathrm{~cm}^{-1}$ from calcite and ankerite in KG [34]. The bands at $870 \mathrm{~cm}^{-1}$ and $1441 \mathrm{~cm}^{-1}$ assured the existence of calcite in KG. As display in Fig. 3.a, the absorption band at $1069 \mathrm{~cm}^{-1}$ was associated to asymmetrical stretching vibrational modes of siloxane ( $\mathrm{Si}-\mathrm{O}-\mathrm{Si}$ ) [35]. The band at $793 \mathrm{~cm}^{-1}$ was associated to Al-O-Si stretching vibration related to the clays in KG [36]. Moreover, typical bands of PANI were found at $1516 \mathrm{~cm}^{-1}$ and $1451 \mathrm{~cm}^{-1}$ are attributed with the benzene ring stretching of $\mathrm{C}=\mathrm{C}-\mathrm{C}$ bonds. These bands that are called as stretching vibrations of $\mathrm{N}=\mathrm{Q}=\mathrm{N}$ and $\mathrm{N}-\mathrm{B}-\mathrm{N}(\mathrm{Q}=$ quinoid and $\mathrm{B}=$ benzoid $)$ are in perfect agreement with those reported other work [26]. The bands at $1322 \mathrm{~cm}^{-1}$ and $1208 \mathrm{~cm}^{-1}$ are due to $\mathrm{C}-\mathrm{N}$ bend vibration, in groupings of the systems $\mathrm{B}$ and $\mathrm{Q}$. Furthermore, the band at $806 \mathrm{~cm}^{-1}$ corresponds to $-\mathrm{C}-\mathrm{N}$ out of plane bending vibrations of $\mathrm{C}-\mathrm{H}$ in the benzene ring. Around $3271 \mathrm{~cm}^{-1}$, it was observed an absorption band for $\mathrm{N}-\mathrm{H}$ stretching of the amine group. In addition, the most changes resulting in PANI@KG was the appearance of the three bands at $1320 \mathrm{~cm}^{-1}, 1441 \mathrm{~cm}^{-1}$ and $1504 \mathrm{~cm}^{-1}$ attributed to the vibration of $\mathrm{C}-\mathrm{N}, \mathrm{CO}_{3}{ }^{2-}$ and $\mathrm{C}=\mathrm{C}-\mathrm{C}$, respectively. The stretching vibration of $\mathrm{Si}-\mathrm{O}-\mathrm{Si}$ showing a displacement to $1063 \mathrm{~cm}^{-1}$ compared with that of KG which confirms that the synthesized product was indeed PANI@KG.

The surface areas and also pore size distributions of samples were investigated by the Brunauer-Emmett-Teller (BET) method (Fig. 4-a). All the materials exhibited the isotherm of type III and similar $\mathrm{H}_{3}$ hysteresis loop. The obtained BET surface areas of PANI, KG and PANI@KG are found to be $7.6 \mathrm{~m}^{2} \cdot \mathrm{g}^{-1}, 12.9 \mathrm{~m}^{2} \cdot \mathrm{g}^{-1}$ and $22.9 \mathrm{~m}^{2} \cdot \mathrm{g}^{-1}$ respectively. The BET areas, total pores and mesoporous volumes of adsorbents are provided in Table 2. The surface area is greater for PANI@KG compared to PANI and KG which shows the presence of more surface active sites for adsorption [37]. 

loss $(1.14 \%)$ below $295^{\circ} \mathrm{C}$, which was associated to loss of $\mathrm{H}_{2} \mathrm{O}$ and solvent molecule. The second weight loss $(4.22 \%)$ in range between $295^{\circ} \mathrm{C}$ and $372^{\circ} \mathrm{C}$ was attributed to breaking chemical bonds of polymer chain from their frameworks. At $900^{\circ} \mathrm{C}$, the global amount loss of nanocomposite was $21.43 \%$, while polymer was $67.82 \%$. The cause is that the existence of $\mathrm{KG}$ on polymer matrix promoted the growth of the crystal [38]. It was determined that PANI@KG had preferable thermal stability than pure PANI.

The PANI@KG was characterized through (TEM) in order to analyze the surface morphology and compare it to the KG and PANI as in Fig. 5. TEM image of nanocomposite exhibit that $\mathrm{KG}$ is homogenously dispersed and these particles are surrounded by polymer matrix with less degree of aggregations which confirms the crystallinity of the PANI@KG. Moreover, the KG shows obvious lattice fringes. While PANI shows a classically morphology and much dark structure with homogenous distribution [22-25]. Moreover, the elemental chemical composition (wt\%) of the PANI@KG nanocomposite used in this study was: C: 11.79; O: 26.84; Si: 31.51; Na: 4.21; Mg: 2.54; Al: 12.15; S: 1.59; K: 2.98 and Fe: 6.48. The chemical compositions of PANI and KG are reported in Table 3.

\subsection{Adsorption of BPA}

\subsubsection{Influence of $\mathrm{pH}$}

The optimized solution's $\mathrm{pH}$ is a key factor to maximize the organic pollutants removal on the used adsorbent surface since the solution's $\mathrm{pH}$ influence various factors in the elimination method including a surface charge of the adsorbent, organic ion distribution, and dissociation rate of the functional group found on adsorbent active sites. The removal process 
was investigated under various solutions' $\mathrm{pH}$ in range of 2 to 12 . The influence of $\mathrm{pH}$ on the adsorbed BPA amount are displayed in Fig. 6-a. As it is clear, when $\mathrm{pH}$ increased to 6.0, the removal capacity of KG to BPA rose. This is because BPA commences to partly dissociated, and BPA BPA is no longer on molecular form in the solution, but part of monoanions (HBPA $\left.{ }^{-}\right)$ shows. The KG surface is positively charge, and the electrostatic attractions betwixt this adsorbent and $\mathrm{HBPA}^{-}$fosters the removal. The after increase in $\mathrm{pH}$ produced in decrease in the removal capacity of adsorbents to BPA. This is because the $\pi-\pi$ electron donor/acceptor interaction and H-bonding between adsorbent and BPA is little when the solution $\mathrm{pH}$ is superior to the $\mathrm{pK}_{\mathrm{a}}$ of BPA [39]. Moreover, the removal capacity of BPA by PANI@KG increased at initial and then reduced with the rises of $\mathrm{pH}$, and the maximum removal capacity occurred near $\mathrm{pH}$ 6.0. With the increase of $\mathrm{pH}$, also the dissociation of BPA increases. The augmentation in $\mathrm{HBPA}^{-}$leads to boosted electrostatic attraction between BPA and PANI@KG. When the $\mathrm{pH}$ continues to increase, BPA also dissociates to product the more negative dianion $\left(\mathrm{BPA}^{2-}\right)$, which produces repulsion with the surface of PANI@KG, lead to diminution in the removal capacity [40]. Meanwhile, the elimination of BPA by PANI was the high when the $\mathrm{pH}$ was weak i.e. from 2.0 to 6.0 , with small differences. A limited in BPA elimination was detected as the solution $\mathrm{pH}$ was augmented from $\mathrm{pH} 6.0$ to 12.0. This remark was attributed to the hypothesis that, in alkaline condition, a negative charged is formed on the PANI surfaces, and correspondingly, the $-\mathrm{OH}$ functions become deprotonated to form $\mathrm{HBPA}^{-}$and $\mathrm{BPA}^{2-}$. This resulted in repulsion between the PANI chain and BPA ions.

\subsubsection{Effect of adsorption time}

Contact time is another important building block to get the maximum BPA ion removal by the materials adsorbents. Fig. 6.b. Percentage removal of the BPA ions at various time 
intervals were studied by using $1 \mathrm{~g} / 25 \mathrm{~mL}$ adsorbent for a concentration of $500 \mathrm{mg} . \mathrm{L}^{-1}$ at a $\mathrm{pH}$ of 6.0 and at $25^{\circ} \mathrm{C}$. As can be seen, all specimens showed similar trends. As time goes, BPA ion removal increases speedy to reach an optimum time point attributed to the presence of the vacant sites on the adsorbents surfaces. Then, the adsorption ratio remains nearly constant due to saturated of the adsorbents active sites. Moreover, the figure confirms that the maximum adsorption of the selected BPA ions on the prepared adsorbents could be obtained by adopting a 120 min contact time. As it was discussed, increasing the contact time did not result in the BPA ion adsorption increase, on adsorbents surface.

\subsubsection{Adsorption kinetics}

Adsorption kinetics of BPA ions on three adsorbents was analyzed by employing pseudo-first-order (PFO) and pseudo-second-order (PSO) models. The kinetics was studied for the adsorption of BPA ions having the initial concentration of $500 \mathrm{mg} \cdot \mathrm{L}^{-1}$.

The PFO kinetics describes the adsorption occurring between solid/liquid systems depending upon the removal capability of adsorbents [41]. The linear equation for PSO kinetics is equated as follows [42]:

$$
\log \left(Q_{e}-Q_{t}\right)=\log Q_{e}-\frac{k_{1}}{2.303} t
$$

Where, $Q_{e}$ and $Q_{t}$ are the equilibrium concentration and concentration at time $t$ of BPA (mg. $\left.\mathrm{g}^{-1}\right)$ respectively and $k_{l}$ being the PFO rate constant $\left(\mathrm{min}^{-1}\right)$ of adsorption. The PFO linear fitting plot of $\log \left(Q_{e}-Q_{t}\right) v s t$ gives a poor correlation coefficient (Table 3) showing that the first order kinetic model was not followed by the adsorption process. 
The linear equation is written as follows:

$$
\frac{t}{Q_{t}}=\frac{1}{k_{2} Q_{e}^{2}}+\frac{1}{Q_{e}} t
$$

where, $k_{2}$ denotes the PSO rate constant $\left(\mathrm{g} \cdot \mathrm{mg}^{-1} \cdot \mathrm{min}\right), Q_{e}$ and $Q_{t}$ represents the

\subsection{Adsorption isotherms of BPA}

The adsorption isotherm gives the amount of BPA adsorbed by adsorbent materials at a fixed temperature in Fig. 6-c. The Freundlich and Langmuir isotherms have been adopted to fit the experimental values.

The Langmuir isotherm explains the adsorbent surface to be uniform containing fixed number of adsorption sites and also the adsorption is monolayer. The linear equation for Langmuir isotherm can be written as follows [45]: 


$$
\frac{C_{e q}}{Q_{e q}}=\frac{1}{K_{l} C_{m}}+\frac{C_{e q}}{Q_{m}}
$$

Where $Q_{e q}$ is the amount adsorbed $\left(\mathrm{mg}^{-\mathrm{g}^{-1}}\right), C_{e q}$ is the equilibrium concentration of the

258 adsorbate $\left(\mathrm{mg} . \mathrm{L}^{-1}\right), K_{l}\left({\left.\mathrm{~L} . \mathrm{mg}^{-1}\right)}^{-1}\right.$ are Langmuir constants and $Q_{m}\left(\mathrm{mg} \cdot \mathrm{g}^{-1}\right)$ is the maximum adsorption capacity of adsorbent.

Both physisorption (multilayer) and chemisorption (monolayer) can be determined applied the Freundlich isotherm. This type is based on the heterogeneous equilibrium on adsorbent surface. The equation for Freundlich isotherm is as follows [46]:

$$
\operatorname{Ln} Q_{e q}=\operatorname{Ln} K_{f}+\frac{1}{n} \operatorname{Ln} C_{e q}
$$

where $K_{f}\left(\mathrm{mg}^{1-1 / \mathrm{n}} \cdot \mathrm{L}^{1 / \mathrm{n}} \cdot \mathrm{g}^{-1}\right)$ and $\mathrm{n}$ are the Freundlich isotherm constants which refers to capacity and intensity of adsorption, respectively, and $C_{e q}$ is referred as equilibrium concentration $\left(\mathrm{mg} \cdot \mathrm{L}^{-1}\right)$.

The matching result of adsorption isotherm applied Langmuir and Freundlich types are summarized in Table 5. Several investigators suppose that $\mathrm{n}$ displays a high affinity between adsorbate and adsorbent and also the appearance of chemisorption when major than unities [47]. Since the correlation coefficient $\left(R^{2}\right)$ are found to be $0.977,0.961$ and 0.991 correspond to KG, PANI and PANI@KG adsorbents, respectively. The adsorption results of BPA fit well with Freundlich isotherm. Furthermore, one possible cause for the preferable performance of the formed PANI@KG adsorbent is the elimination mechanism, which appears in both anion exchanges on adsorbents surface by hydrogen-bonding with $\pi-\pi$ liaisons. A comparison of relative adsorption using different adsorbent materials using literature has been summarized in table $6[48-56]$. 


\subsection{Adsorption mechanism}

The presence of polymer matrix on KG surface reasons the surface to be negatively charged which play a significant role in this adsorption process. The removal mechanism can be clarified in two methods. Physisorption can be produced on PANI surface or in KG porosity or chemisorption by interaction between PANI and BPA ions. Therefore, the surface area determined from BET analysis plays a substantial role in the electrostatic attraction process thereby favouring the effective removal process. From BET analysis, the surface area of PANI@KG is greater than PANI and KG thereby indicating that hybrid material exhibits more excellent adsorption performance for BPA than others. Moreover, the presence of quinone and benzene groups with delocalized $\pi$-conjugated structures and electrochemically active sites in the PANI matrix forming an additional agent on the $\mathrm{KG}$ surface and enhance the favorable adsorption of BPA ions.

\subsection{Reuse of adsorbent}

The reusability has been studied in a qualitative manner for three adsorbent materials since the reusability may be crucially important parameter for keeping the process cost down and reduce waste. After desorption process, the adsorbent was washed repeatedly several times with $\mathrm{C}_{2} \mathrm{H}_{5} \mathrm{OH}$ and distilled $\mathrm{H}_{2} \mathrm{O}$. The reusability results are present in Fig. 6-d. The PANI showed decreasing in the adsorption capacity after six cycles of adsorption-desorption process under optimized conditions of $\mathrm{pH} 6.0,1 \mathrm{~g} / 25 \mathrm{~mL}$ of adsorbent dosage and initial BPA concentration of $500 \mathrm{mg} \cdot \mathrm{L}^{-1}$. On the other hand, the adsorption capacity of the KG material decreased from $21.53 \%$ to $7.03 \%$ after also six cycles. However, in the PANI@KG still possessed better adsorption capacity than PANI and KG after five cycles. Besides, the removal 
efficiency was higher than $80 \%$ even after three cycles indicating that the synthesized hybrid material acts as an effective adsorbent in the removal of BPA.

\section{Conclusions}

This study investigated the preparation of new adsorbent based PANI and KG. The characterizations of the materials obtained were carried out by XPS, XRD, FTIR, TGA, SEM and $\mathrm{N}_{2}$ adsorption-desorption isotherms. The adsorption capacity of the PANI, KG and PANI@KG were tested on BPA ions from aqueous solutions at $298 \mathrm{~K}$ and pH 6.0 and the maximum capacity of adsorption was observed to be $63.68 \mathrm{mg} \cdot \mathrm{g}^{-1}$ which is obtained from Langmuir adsorption isotherm by hybrid adsorbent PANI@KG. Besides, the PSO was more consistent with the obtained experimental data. The type of adsorption is found to chemisorption from the kinetic measurements. Further, the PANI@KG possessed highest adsorption capacity after six cycles of adsorption-desorption process. Moreover above $80 \%$ of removal percentage was obtained even after three recycles. Hence we expect that this organicinorganic hybrid can be selected as a potential candidate for water treatment.

\section{Acknowledgements}

Authors gratefully acknowledge the Algerian MESRS and also Instituto Universitario de Materiales of Alicante University (Spain) for the co-operation availing.

Funding information: There is no financial sources funding regarding of this study.

Declaration of Competing Interest: The authors declare that they have no known competing financial interests or personal relationships that could have appeared to influence the work reported in this manuscript. 


\section{References}

321 [1] S.A. Hoshyar, H.A.H. Barzani, Y. Yardım Z. Şentürk. The effect of CTAB, a cationic

322 surfactant, on the adsorption ability of the boron-doped diamond electrode: Application for voltammetric sensing of Bisphenol A and Hydroquinone in water samples. Colloids and Surfaces A: Physicochemical and Engineering Aspects. 610 (2021) 125916.

[2] M.V.L. Ramón, R.O. Pérez, M.I.B. Toledo, J.R. Utrilla, C.M. Castilla, M.S. Polo. Removal of bisphenols $\mathrm{A}$ and $\mathrm{S}$ by adsorption on activated carbon clothes enhanced by the presence of bacteria. Science of the Total Environment. 669 (2019) 767-776.

[3] X. Men, Q. Guo, B. Meng, S. Ren, B. Shen. Adsorption of bisphenol A in aqueous solution by composite bentonite with organic moity. Microporous and Mesoporous Materials. 308 (2020) 110450.

[4] R. Rezg, S. El-Fazaa, N. Gharbi, B. Mornagui. Bisphenol A and human chronic diseases: current evidences, possible mechanisms, and future perspectives. Environment International. 64 (2014) 83-90.

[5] Y.Q. Huang, C.K.C. Wong, J.S. Zheng, H. Bouwman, R. Barra, B. Wahlström, L. Neretin, M.H. Wong. Bisphenol A (BPA) in China: a review of sources, environmental levels, and potential human health impacts. Environment International. 42 (2012) 91-99

[6] A. Careghini, A.F. Mastorgio, S. Saponaro, E. Sezenna. Bisphenol A, nonylphenols, benzophenones, and benzotriazoles in soils, groundwater, surface water, sediments, and food: a review. Environmental Science and Pollution Research. 22 (2015) 5711-5741. 
[7] D.C. Arriagada. Elucidating the co-transport of bisphenol A with polyethylene terephthalate (PET) nanoplastics: A theoretical study of the adsorption mechanism. Environmental Pollution. 270 (2021) 116192

[8] J. Sharma, I.M. Mishra, V. Kumar. Degradation and mineralization of Bisphenol A (BPA) in aqueous solution using advanced oxidation processes: UV/H2O2 and UV/S2O82oxidation systems. Journal of Environmental Management. 156 (2015) 266-275

[9] S.K. Ponnaiah, P. Periakaruppan, S. Muthupandian. Ultrasonic energy-assisted in-situ synthesis of Ru0/PANI/g-C3N4 nanocomposite: Application for picomolar-level electrochemical detection of endocrine disruptor (Bisphenol-A) in humans and animals. Ultrasonics Sonochemistry. 58 (2019) 104629

[10] S.Elakkiya, G.Arthanareeswaran, D.B.Das. Embedding low-cost 1D and 2D iron pillared nanoclay to enhance the stability of polyethersulfone membranes for the removal of bisphenol A from water. Separation and Purification Technology. 266 (2021) 118560

[11] L.H. Yeh, Z.Y. Huang, Y.C. Liu, M.J. Deng, T.H. Chou, H.C.O. Yang, T. Ahamad, S.M. Alshehri, K.C.W. Wu. A nanofluidic osmotic power generator demonstrated in polymer gel electrolytes with substantially enhanced performance. Journal of Materials Chemistry A. 7 (2019) 26791-26796.

[12] L. Joseph, L.K. Boateng, J.R.V. Flora, Y.G. Park, A. Son, M. Badawy, Y. Yoon. Removal of bisphenol A and 17 $\alpha$-ethinyl estradiol by combined coagulation and adsorption using carbon nanomaterials and powdered activated carbon. Separation and Purification Technology. 107 (2013) 37-47 
[13] X. Xiao, R. Hao, M. Liang, X.X. Zuo, J.M. Nan, L.S. Li, W.D. Zhang. One-pot solvothermal synthesis of three-dimensional (3D) $\mathrm{BiOI} / \mathrm{BiOCl}$ composites with enhanced visible-light photocatalytic activities for the degradation of bisphenol-A. Journal of Hazardous Materials. 233-234 (2012) 122-130

[14] M.K. Ji, A.N. Kabra, J. Choi, J.H. Hwang, J.R. Kim, R.A.I. Abou-Shanab, Y.K. Oh, B.H. Jeon. Biodegradation of bisphenol A by the freshwater microalgae Chlamydomonas mexicana and Chlorella vulgaris. Ecological Engineering. 73 (2014) 260-269.

[15] G. Sheng, H. Dong, Y. Li. Characterization of diatomite and its application for the retention of radiocobalt: role of environmental parameters. Journal of Environmental Radioactivity. 113 (2012) 108-115.

[16] K. Khezri, M. Ghasemi, Y. Fazli. Effect of Mesoporous Diatomite Particles on the Kinetics of SR\&NI ATRP of Styrene and Butyl Acrylate. Zeitschrift für Physikalische Chemie. 232 (2018) 1-17

[17] W. Tsai, C. Lai, K. Hsien. Characterization and adsorption properties of diatomaceous earth modified by hydrofluoric acid etching. Journal of Colloid and Interface Science. 297 (2006) 749-754.

[18] T. Qian, J. Li, H. Ma. Adjustable thermal property of polyethylene glycol/diatomite shapestabilized composite phase change material. Polymer Composites. 37 (2016) 854-860.

[19] K. Khaldi, M. Hadjel, A. Benyoucef. Removal of Quinmerac by Diatomite and Modified Diatomite from Aqueous Solution. Surface Engineering and Applied Electrochemistry. 54 (2018) 194-202 
[20] N. Caliskan, A. R. Kul, S. Alkan, E. G. Sogut, I. Alacabey. Adsorption of Zinc(II) on diatomite and manganese-oxide-modified diatomite: A kinetic and equilibrium study. Journal of Hazardous Materials. 193 (2011) 27-36.

[21] I. Toumi, H. Djelad, F. Chouli, A. Benyoucef. Synthesis of PANI@ZnO Hybrid Material and Evaluations in Adsorption of Congo Red and Methylene Blue Dyes: Structural Characterization and Adsorption Performance. Journal of Inorganic and Organometallic Polymers and Materials. doi.org/10.1007/s10904-021-02084-0

[22] A. Bekhoukh, I. Moulefera, F.Z. Zeggai, A. Benyoucef, K. Bachari. Anionic Methyl Orange Removal from Aqueous Solutions by Activated Carbon Reinforced Conducting Polyaniline as Adsorbent: Synthesis, Characterization, Adsorption Behavior, Regeneration and Kinetics Study. Journal of Polymers and the Environment. doi.org/10.1007/s10924-021-02248-6

[23] O. Mahi, K. Khaldi, M. S. Belardja, A. Belmokhtar, A. Benyoucef. Development of a New Hybrid Adsorbent from Opuntia Ficus Indica NaOH Activated with PANI Reinforced and Its Potential Use in Orange $G$ Dye Removal. Journal of Inorganic and Organometallic Polymers and Materials. 31 (2021) 2095-2104.

[24] M.A. Bekhti, M.S. Belardja, M. Lafjah, F. Chouli, A. Benyoucef. Enhanced tailored of thermal stability, optical and electrochemical properties of PANI matrix containing $\mathrm{Al}_{2} \mathrm{O}_{3}$ hybrid materials synthesized through in situ polymerization. Polymer Composites. 42 (2021) 6-14 
[25] E.T. Kang, K.G. Neoh, K.L. Tan. Polyaniline: a polymer with many interesting intrinsic redox states. Progress in Polymer Science. 23 (1998) 277-324.

[26] T. Ahamad, M. Naushad, Y. Alzaharani, S.M. Alshehri. Photocatalytic degradation of bisphenol-A with $\mathrm{g}-\mathrm{C}_{3} \mathrm{~N}_{4} / \mathrm{MoS}_{2}$-PANI nanocomposite: Kinetics, main active species, intermediates and pathways. Journal of Molecular Liquids. 311 (2020) 113339

[27] X. Li, X. Li, G. Wang. Surface modification of diatomite using polyaniline. Materials Chemistry and Physics. 102 (2007) 140-143

[28] X. Li, X, Li. G. Wang. Fibrillar polyaniline/diatomite composite synthesized by one-step in situ polymerization method. Applied Surface Science. 249 (2005) 266-270.

[29] F. Akti. Photocatalytic degradation of remazol yellow using polyaniline-doped tin oxide hybrid photocatalysts with diatomite support. Applied Surface Science. 455 (2018) 931939

[30] M.P. Cabrera, T.F. da Fonseca. R.V.B. de Souza, C.R.D. de Assis, J.Q. Marcatoma, J.C. Maciel, D.F.M. Neri, F. Soria, L.B.C. Jr. Polyaniline-coated magnetic diatomite nanoparticles as a matrix for immobilizing enzymes. Applied Surface Science. 457 (2018) 21-29.

[31] R. Bhattacharyya, S.K. Ray. Adsorption of industrial dyes by semi-IPN hydrogels of acrylic copolymers and sodium alginate. Journal of Industrial and Engineering Chemistry. 22 (2015) 92-102. 
[32] B. Wang, G. Zhang, X. Leng, Z. Sun, S. Zheng. Characterization and improved solar light activity of vanadium doped $\mathrm{TiO} 2 /$ diatomite hybrid catalysts. Journal of Hazardous Materials. 285 (2015) 212-220.

[33] F.Z. Kouidri, R. Berenguer, A. Benyoucef, E. Morallon. Tailoring the properties of polyanilines/SiC nanocomposites by engineering monomer and chain substituents. Journal of Molecular Structure. 1188 (2019) 121-128

[34] F. Aouadja, F. Bouzerara, C.M. Guvenc, M.M. Demir. Fabrication and properties of novel porous ceramic membrane supports from the (Sig) diatomite and alumina mixtures. Boletín de la Sociedad Española de Cerámica y Vidrio. DOI: 10.1016/j.bsecv.2021.04.002.

[35] J. Mohammed, N.S. Nasri, M.A.A. Zaini, U.D. Hamza, F.N. Ani. Adsorption of benzene and toluene onto $\mathrm{KOH}$ activated coconut shell based carbon treated with NH3. International Biodeterioration \& Biodegradation. 102 (2015) 245-255.

[36] H. Nefzi, M. Abderrabba, S. Ayadi, J. Labidi . Formation of Palygorskite Clay from Treated Diatomite and its Application for the Removal of Heavy Metals from Aqueous Solution. Water. 10 (2018) 1257.

[37] S.P. Gupta, H.H. Nishad, S.D. Chakane, S.W. Gosavi, D.J. Late, P.S. Walke. Phase transformation in tungsten oxide nanoplates as a function of post-annealing temperature and its electrochemical influence on energy storage. Nanoscale Advances. 2 (2020) 46894701. 
[38] G. Sharma, B. Thakur, A. Kumar, S. Sharma, M.Naushad, F.J. Stadler. Atrazine removal using chitin-cl-poly(acrylamide-co-itaconic acid) nanohydrogel: Isotherms and $\mathrm{pH}$ responsive nature. Carbohydrate Polymers. 241 (2020) 116258.

[39] M.B. Ahmed, J.L. Zhou, H.H. Ngo, M.A. Johir, K. Sornalingam. Sorptive removal of phenolic endocrine disruptors by functionalized biochar: Competitive interaction mechanism, removal efficacy and application in wastewater. Chemical Engineering Journal. 335 (2018) 801-811

[40] J. Wang, M. Zhang. Adsorption Characteristics and Mechanism of Bisphenol A by Magnetic Biochar. International Journal of Environmental Research and Public Health. 17 (2020) 1075.

[41] H.Y. Shan. Citation review of Lagergren kinetic rate equation on adsorption reactions. Scientometrics. 59 (2004) 171-177.

[42] S. Lagergren. Zur Theorie der Sogenannten Adsorption Gelöster Stoffe, Kungliga Svenska Vetenskapsakademiens. Handlingar. 24 (1898) 1-39

[43] S. Azizian. Kinetic models of sorption: a theoretical analysis. Journal of Colloid and Interface Science. 276 (2004) 47-52

[44] F. Wang, X. Lu, W. Peng, Y. Deng, T. Zhang, Y. Hu, X.Y. Li. Sorption Behavior of Bisphenol A and Triclosan by Graphene: Comparison with Activated Carbon. ACS Omega. 2 (2017) 5378-5384. 
460 [45] I. Langmuir. The adsorption of gases on plane surfaces of glass, mica and platinum. Journal of the American Chemical Society. 40 (1918) 1361-1403

462

463

464

465

466

467

468

469

470

471

472

473

474

475

476

477

478

[46] H.M.F. Freundlich. Over the Adsorption in Solution. Journal of Physical Chemistry. 57 (1906) 385-471

[47] J. Wang, G. Liu, T. Li, C. Zhou. Physicochemical studies toward the removal of Zn(ii) and $\mathrm{Pb}(\mathrm{ii})$ ions through adsorption on montmorillonite-supported zero-valent iron nanoparticles. RSC Advances. 5 (2015) 29859.

[48] M.H. Dehghani, M. Ghadermazi, A. Bhatnagar, P. Sadighara, G.J. Khaniki, B. Heibati, G. McKay. Adsorptive removal of endocrine disrupting bisphenol A from aqueous solution using chitosan. Journal of Environmental Chemical Engineering. 4 (2016) 2647-2655.

[49] R. Wirasnita, T. Hadibarata, A.R.M. Yusoff, Z. Yusop. Removal of bisphenol A from aqueous solution by activated carbon derived from oil palm empty fruit bunch. Water, Air, \& Soil Pollution. 225 (2014) 2148.

[50] A. Nakanishi, M. Tamai, N. Kawasaki, T. Nakamura, S. Tanada. Adsorption characteristics of bisphenol A onto carbonaceous materials produced from wood chips as organic waste. Journal of Colloid and Interface Science. 252 (2002) 393-396.

[51] Y. Zhou, L. Chen, P. Lu, X. Tang, J. Lu. Removal of bisphenol A from aqueous solution using modified fibric peat as a novel biosorbent. Separation and Purification Technology 81 (2011) 184-190. 
[52] X. Men, Q. Guo, B. Meng, S. Ren, B. Shen. Adsorption of bisphenol A in aqueous solution by composite bentonite with organic moity. Microporous and Mesoporous Materials. 308 (2020) 110450.

[53] Q. Zhou, Y. Wang, J. Xiao, H. Fan.. Adsorption and removal of bisphenol A, $\alpha$-naphthol and $\beta$-naphthol from aqueous solution by $\mathrm{Fe}_{3} \mathrm{O}_{4} @$ polyaniline core-shell nanomaterials. Synthetic Metals. 212 (2016) 113-122.

[54] Q. Zhou, Y. Wang, J. Xiao, H. Fan.. Fabrication and characterisation of magnetic graphene oxide incorporated $\mathrm{Fe}_{3} \mathrm{O}_{4} @$ polyaniline for the removal of bisphenol A, t-octylphenol, and $\alpha$-naphthol from water. Scientific Reports. 7 (2017) 11316.

[55] M. Zeeshan, J. Shah, M.R. Jan, M. Iqbal. Removal of Bisphenol-A from Aqueous Samples Using Graphene Oxide Assimilated Magnetic Silica Polyaniline Composite. Journal of Inorganic and Organometallic Polymers and Materials. 31 (2021) 2073-2082

[56] D. Bhatia, D. Datta. Removal of Bisphenol-A Using Amine-Modified Magnetic Multiwalled Carbon Nanotubes: Batch and Column Studies. Journal of Chemical \& Engineering Data. 64 (2019) 2877-2887 
Fig. 1. (a) Survey XPS spectra and (b) XRD patterns of KG, PANI and PANI@KG.

500

Fig. 2. XPS core-level spectra of (a) C1s of PANI, (b) C1s of PANI@KG, (c) N1s of PANI and 501 (d) N1s of PANI@KG.

502 Fig. 3. FTIR spectrum of KG, PANI and PANI@KG.

503

Fig. 4. (b) BET surface area and (c) TGA curves of materials

504

Fig. 5. TEM images of: (a) KG ; (b) PANI and (c) PANI@KG.

505 Fig. 6. (a) Effect of pHs on the adsorption capacity, (b) Contact Time $\left(\mathrm{C}_{0}: 500 \mathrm{mg} . \mathrm{L}^{-1} ; \mathrm{pH}: 6.0\right.$; 506 T: 298K; adsorbent dose: 1g), (c) Adsorption isotherms (adsorbent dose: 1g; BPA $25 \mathrm{~mL}$; T: $507298 \mathrm{~K} ; \mathrm{pH}:$ 6.0) and (d) Adsorbent capacity change and first BPA in consecutive cycles 508 (adsorbents dose: 1g; BPA: 25mL; T: 298K; pH 6.0).

509

510

511

512

513

514

515 
516 Table 1. XPS values of Binding Energy (BE) for: (A) PANI, (B) KG and (C) PANI@KG

517 materials.

\begin{tabular}{c|c|c|c|c}
\hline \hline \multirow{2}{*}{ Species } & \multicolumn{3}{|c|}{ Materials and BE $(\mathrm{eV})$} & \multirow{2}{*}{ Remarks } \\
\cline { 2 - 5 } & $(\mathrm{A})$ & $(\mathrm{B})$ & $(\mathrm{C})$ & \\
\hline $\mathrm{Si} 2 \mathrm{p} 3$ & $/ /$ & 102.70 & 102.97 & \multirow{2}{*}{$\mathrm{Si}^{4+}$ in $\mathrm{SiO}_{2}$} \\
\hline $\mathrm{Si} 2 \mathrm{p} 1$ & $/ /$ & 103.43 & 103.50 & \\
\hline $\mathrm{Ca} 2 \mathrm{p} 3$ & $/ /$ & 347.82 & $/ /$ & \multirow{2}{*}{$\mathrm{Ca}^{2+}$ ions } \\
\hline $\mathrm{Ca} 2 \mathrm{p} 1$ & $/ /$ & 350.95 & $/ /$ & $\mathrm{Fe}^{2+}$ ions \\
\hline $\mathrm{Fe} 2 \mathrm{p}$ & $/ /$ & 710.59 & $/ /$ & $\mathrm{C}=\mathrm{O}, \mathrm{O}=\mathrm{C}-\mathrm{OH}$ \\
\hline \multirow{3}{*}{$\mathrm{O} 1 \mathrm{~s}$} & 531.35 & 531.06 & 531.42 & $\mathrm{Si}-\mathrm{O}-\mathrm{Si}, \mathrm{C}-\mathrm{OH}$ \\
\cline { 2 - 4 } & 532.50 & 532.41 & $/ /$ & $\mathrm{Si}-\mathrm{O}-\mathrm{C}, \mathrm{Zn}-\mathrm{OH}, \mathrm{H}_{2} \mathrm{O}$ \\
\cline { 2 - 4 } & 533.74 & $/ /$ & 533.29 & $\mathrm{C}-\mathrm{H}, \mathrm{C}-\mathrm{C}, \mathrm{C}=\mathrm{C}$ \\
\hline \multirow{5}{*}{$\mathrm{C} 1 \mathrm{~s}$} & 284.56 & 284.86 & 284.29 & $\mathrm{C}-\mathrm{N}$ \\
\cline { 2 - 4 } & 285.66 & $/ /$ & 285.64 & $\mathrm{C}-\mathrm{O}$ \\
\cline { 2 - 4 } & 286.94 & $/ /$ & 287.32 & $\mathrm{O}-\mathrm{C}=\mathrm{O}$ \\
\cline { 2 - 4 } & 290.96 & $/ /$ & $/ /$ & $=\mathrm{N}-$ \\
\hline \multirow{3}{*}{$\mathrm{N} 1 \mathrm{~s}$} & 399.45 & $/ /$ & 399.47 & $-\mathrm{NH}-$ \\
\cline { 2 - 4 } & 400.62 & $/ /$ & 400.68 & $\mathrm{~N}^{+}$ \\
\cline { 2 - 4 } $\mathrm{C} 2 \mathrm{p}$ & 401.83 & $/ /$ & 402.16 & $\mathrm{Cl}$ ions \\
\hline \hline
\end{tabular}

518

519 Table 2. Textural properties of materials.

\begin{tabular}{c|c|c|c}
\hline \hline Materials & $\begin{array}{c}\text { BET area } \\
\left(S_{B E T}\right) \mathrm{m}^{2} \cdot \mathrm{g}^{-1}\end{array}$ & $\begin{array}{c}\text { Total pores volume } \\
\left(V_{t}\right) \mathrm{cm}^{3} \cdot \mathrm{g}^{-1}\end{array}$ & $\begin{array}{c}\text { Mesoporous volume } \\
\left(V_{\text {mes }}\right) \mathrm{cm}^{3} \cdot \mathrm{g}^{-1}\end{array}$ \\
\hline PANI & 36.58 & 0.174 & 0.087 \\
\hline KG & 6.47 & 0.029 & 0.027 \\
\hline PANI@KG & 47.82 & 0.179 & 0.059 \\
\hline \hline
\end{tabular}

520

521 Table 3. Chemical composition (wt\%) of samples.

\begin{tabular}{c|cccccccccccc||}
\hline \hline Weight $\%$ & $\mathrm{C}$ & $\mathrm{Si}$ & $\mathrm{O}$ & $\mathrm{S}$ & $\mathrm{Na}$ & $\mathrm{Mg}$ & $\mathrm{Al}$ & $\mathrm{Ca}$ & $\mathrm{K}$ & $\mathrm{Fe}$ & $\mathrm{Cl}$ \\
\hline $\mathrm{KG}$ & $/ /$ & 47.22 & 29.18 & $/ /$ & $/ /$ & 2.47 & 8.17 & 6.86 & 0.21 & 5.66 & 0.23 \\
\hline PANI & 63.21 & 0.79 & 20.70 & 3.38 & 9.88 & $/ /$ & $/ /$ & $/ /$ & $/ /$ & $/ /$ & 3.04 \\
\hline PANI@ KG & 11.79 & 31.51 & 26.84 & 1.59 & 4.21 & 2.54 & 12.15 & $/ /$ & 2.98 & 6.36 & 0.12 \\
\hline \hline
\end{tabular}

522 
523 Table 4. PFO and PSO removal rate constant and $Q_{e q}$ value for elimination of BPA by 524 nanoadsorbents at $298 \mathrm{~K}, \mathrm{pH} 6.0$ and $C_{o} 500 \mathrm{mg} . \mathrm{L}^{-1}$.

\begin{tabular}{|c|c|c|c|c|c|c|c|}
\hline \multirow[b]{2}{*}{ Materials } & \multirow[b]{2}{*}{$\underset{\left(\mathrm{mg}_{\text {eq. }} \mathrm{g}^{-1}\right)}{Q}$} & \multicolumn{3}{|c|}{ PFO } & \multicolumn{3}{|c|}{ PSO } \\
\hline & & $\begin{array}{c}k_{1} \\
\min ^{-1}\end{array}$ & $\begin{array}{l}Q_{\text {eq.Cal }} \\
\text { mg.g }\end{array}$ & $R^{2}$ & $\begin{array}{c}k_{2 . a d s} \\
\text { g.mg } \\
-1 \\
\min ^{-1}\end{array}$ & $\begin{array}{l}Q_{\text {eq.Cal }} \\
\mathrm{mg} \cdot \mathrm{g}^{-1}\end{array}$ & $R^{2}$ \\
\hline PANI & 37.43 & 0.009 & 58.11 & 0.912 & 0.0003 & 35.86 & 0.992 \\
\hline $\mathrm{KG}$ & 14.92 & 0.003 & 28.58 & 0.923 & 0.0014 & 16.38 & 0.997 \\
\hline PANI@KG & 63.68 & 0.416 & 69.65 & 0.907 & 0.0010 & 62.92 & 0.996 \\
\hline
\end{tabular}

525

526 Table 5. Langmuir \& Freundlich isotherms constant and correlation coefficient for removal of

527 BPA on adsorbents at $298 \mathrm{~K}$ and $\mathrm{pH} 6.0$.

\begin{tabular}{c|cccc|ccc}
\hline \hline \multirow{3}{*}{ Adsorbents } & \multicolumn{3}{|c|}{ Langmuir } & \multicolumn{3}{|c}{ Freundlich } \\
\cline { 2 - 8 } & $\begin{array}{c}Q_{m} \\
\left(\mathrm{mg}^{-1}\right)\end{array}$ & $\begin{array}{c}K_{L} \\
\left(\mathrm{~L} . \mathrm{mg}^{-1}\right)\end{array}$ & $R_{L}$ & $R^{2}$ & $\begin{array}{c}K_{F} \\
\left(\mathrm{mg}^{1-1 / \mathrm{n}} \mathrm{L}^{1 / \mathrm{n}} \mathrm{g}^{-1}\right)\end{array}$ & $n$ & $R^{2}$ \\
\hline PANI & 22.93 & 0.114 & 0.275 & 0.846 & 2.477 & 1.95 & 0.977 \\
\hline KG & 6.37 & 1.097 & 0.125 & 0.908 & 4.017 & 4.37 & 0.961 \\
\hline PANI@KG & 56.81 & 0.080 & 0.180 & 0.699 & 8.678 & 2.35 & 0.991 \\
\hline \hline
\end{tabular}

528

529

530

531

532

533

534

535 
536 Table 6. Adsorption capacities $\left(Q_{e q}\right)$ of BPA on various adsorbents.

\begin{tabular}{|c|c|c|c|}
\hline Adsorbents & $\begin{array}{c}Q_{e q} \\
\left(\mathrm{mg} \cdot \mathrm{g}^{-1}\right)\end{array}$ & $\mathrm{pH}$ & Ref. \\
\hline Synthesized chitosan & 34.00 & 5.0 & [48] \\
\hline Activated carbon & 41.00 & 5.0 & [49] \\
\hline Sugi chip & 11.50 & 7.0 & {$[50]$} \\
\hline Modified fibric peat & 29.15 & // & [51] \\
\hline Composited modified bentonite CPAB/EGIS/B & 119 & 7.0 & [52] \\
\hline $\mathrm{CPAB} / \mathrm{B}$ & 27.87 & 7.0 & {$[52]$} \\
\hline EGIS/B & 97.52 & 7.0 & {$[52]$} \\
\hline Fe3O4@polyaniline core-shell & 9.13 & 7.0 & [53] \\
\hline Graphene oxide incorporated $\mathrm{Fe}_{3} \mathrm{O}_{4} @$ polyaniline & 14.43 & 6.0 & [54] \\
\hline $\mathrm{Fe}_{3} \mathrm{O}_{4} @ \mathrm{SiO}_{2} @$ polyaniline graphene oxide & 454.56 & 6.0 & {$[55]$} \\
\hline Magnetic Multiwalled Carbon Nanotube & 21.43 & // & {$[56]$} \\
\hline PANI@KG & 63.68 & 6.0 & This work \\
\hline
\end{tabular}


Figures

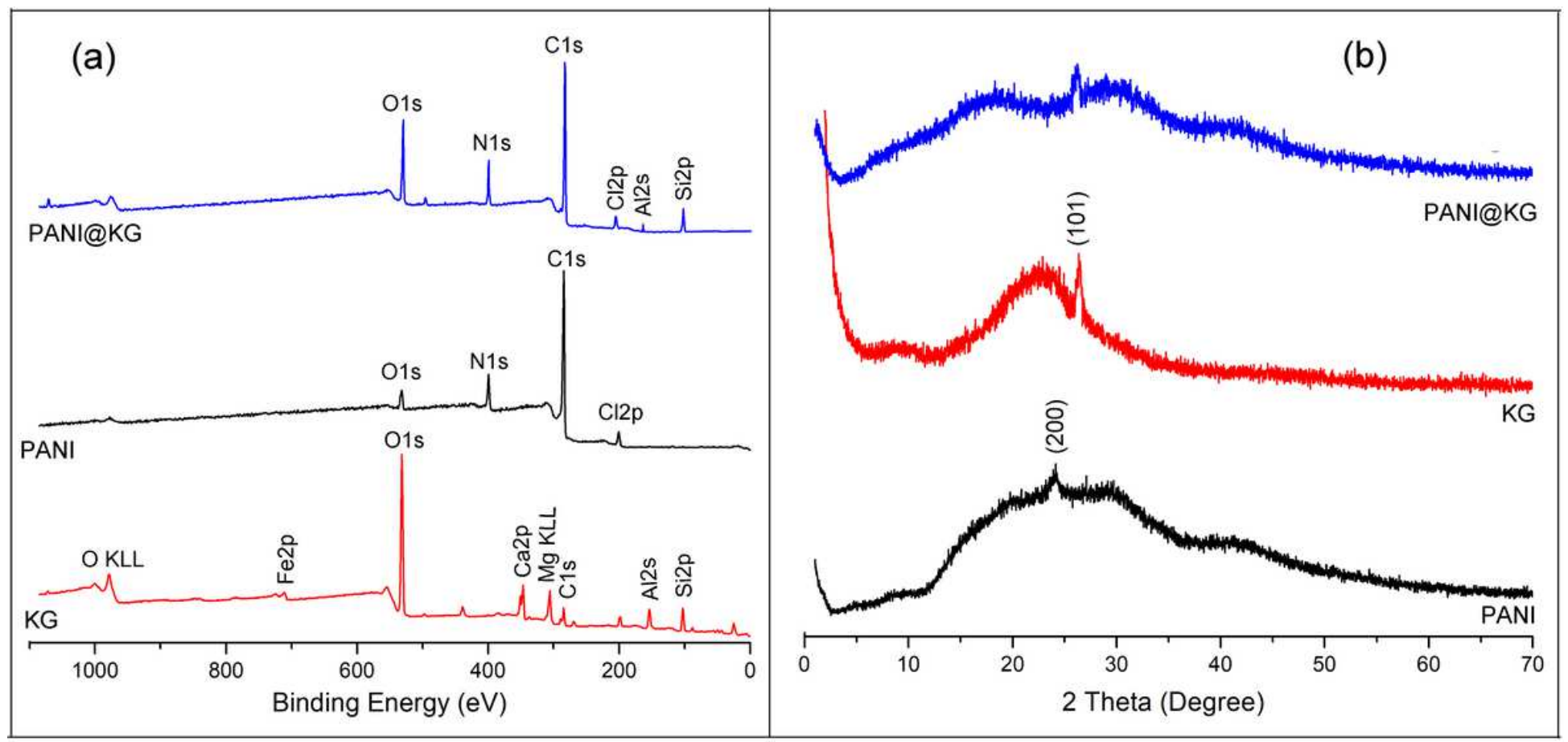

Figure 1

(a) Survey XPS spectra and (b) XRD patterns of KG, PANI and PANI@KG. 


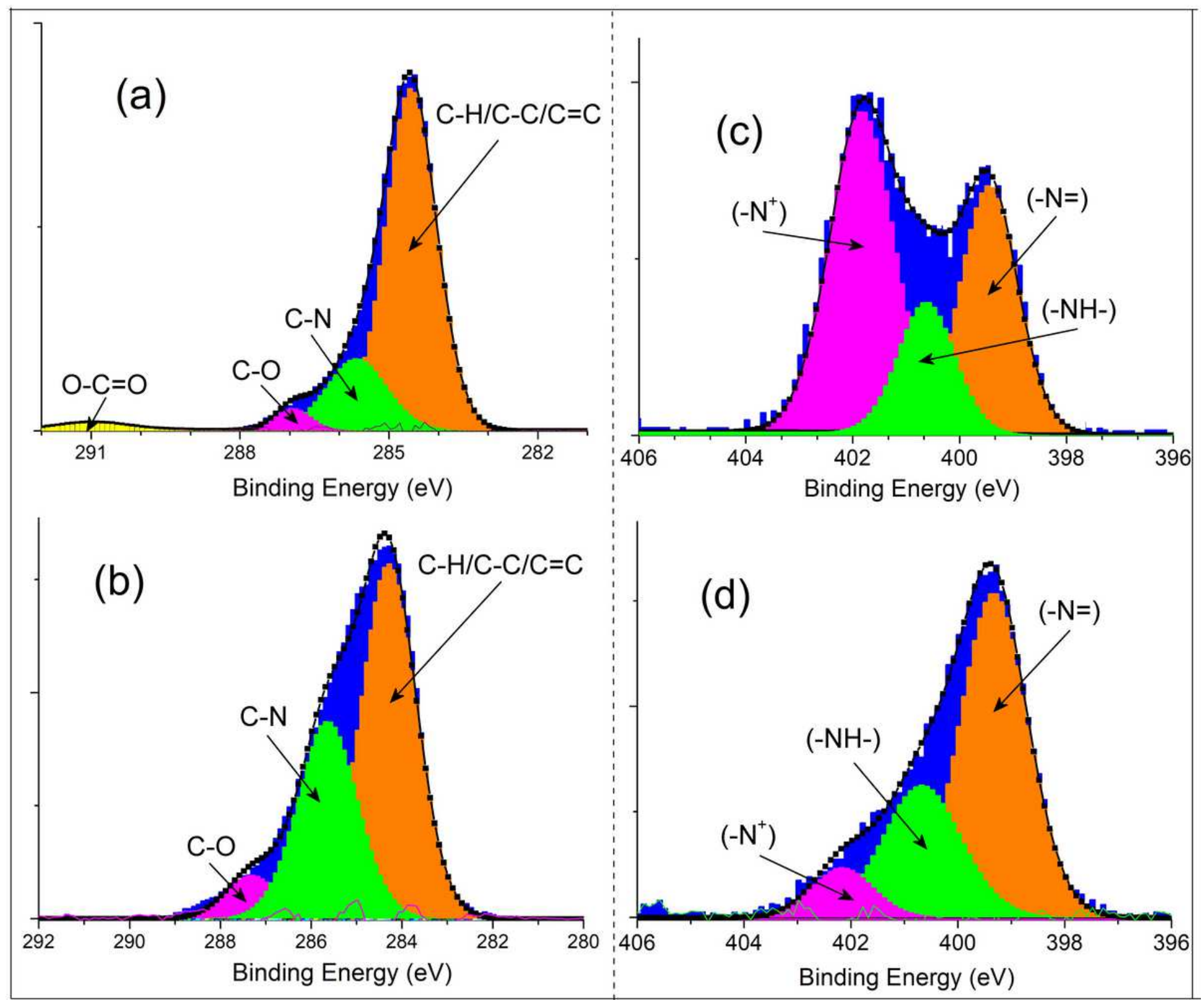

Figure 2

XPS core-level spectra of (a) C1s of PANI, (b) C1s of PANI@KG, (c) N1s of PANI and (d) N1s of PANI@KG. 


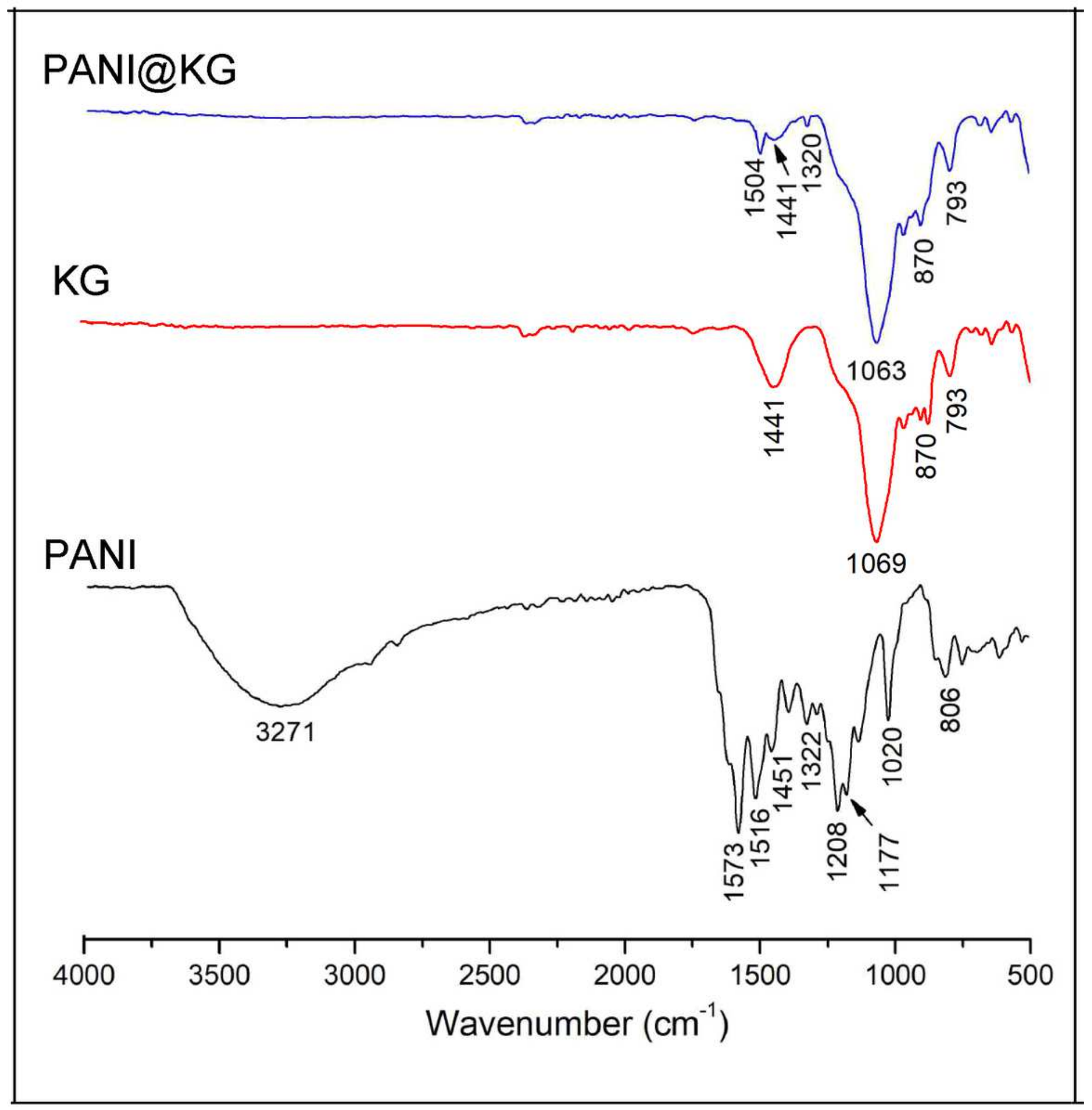

Figure 3

FTIR spectrum of KG, PANI and PANI@KG. 


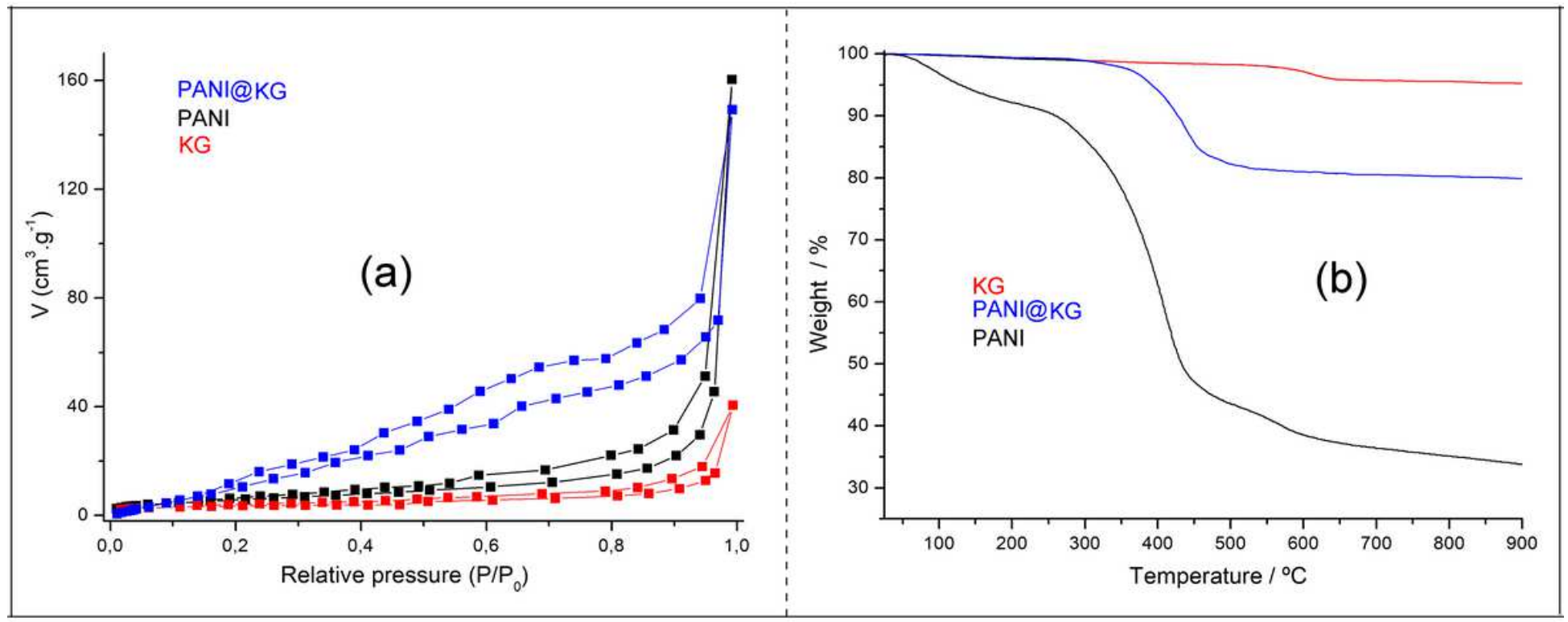

Figure 4

(a) BET surface area and (b) TGA curves of materials
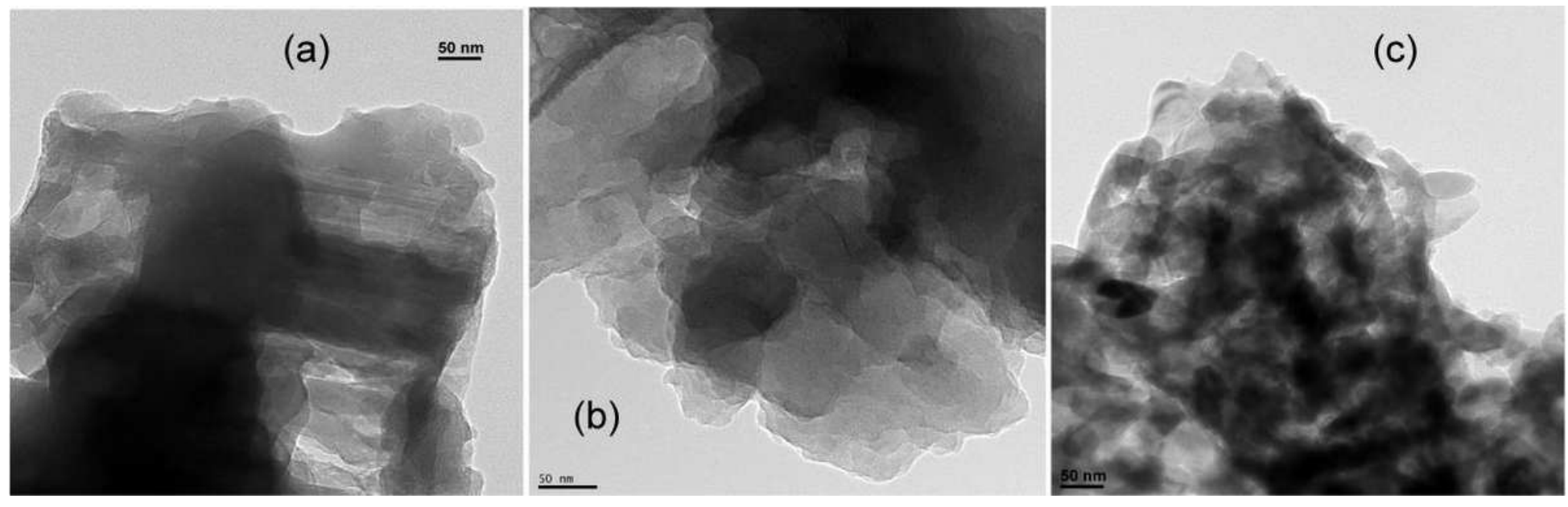

Figure 5

TEM images of: (a) KG ; (b) PANI and (c) PANI@KG. 


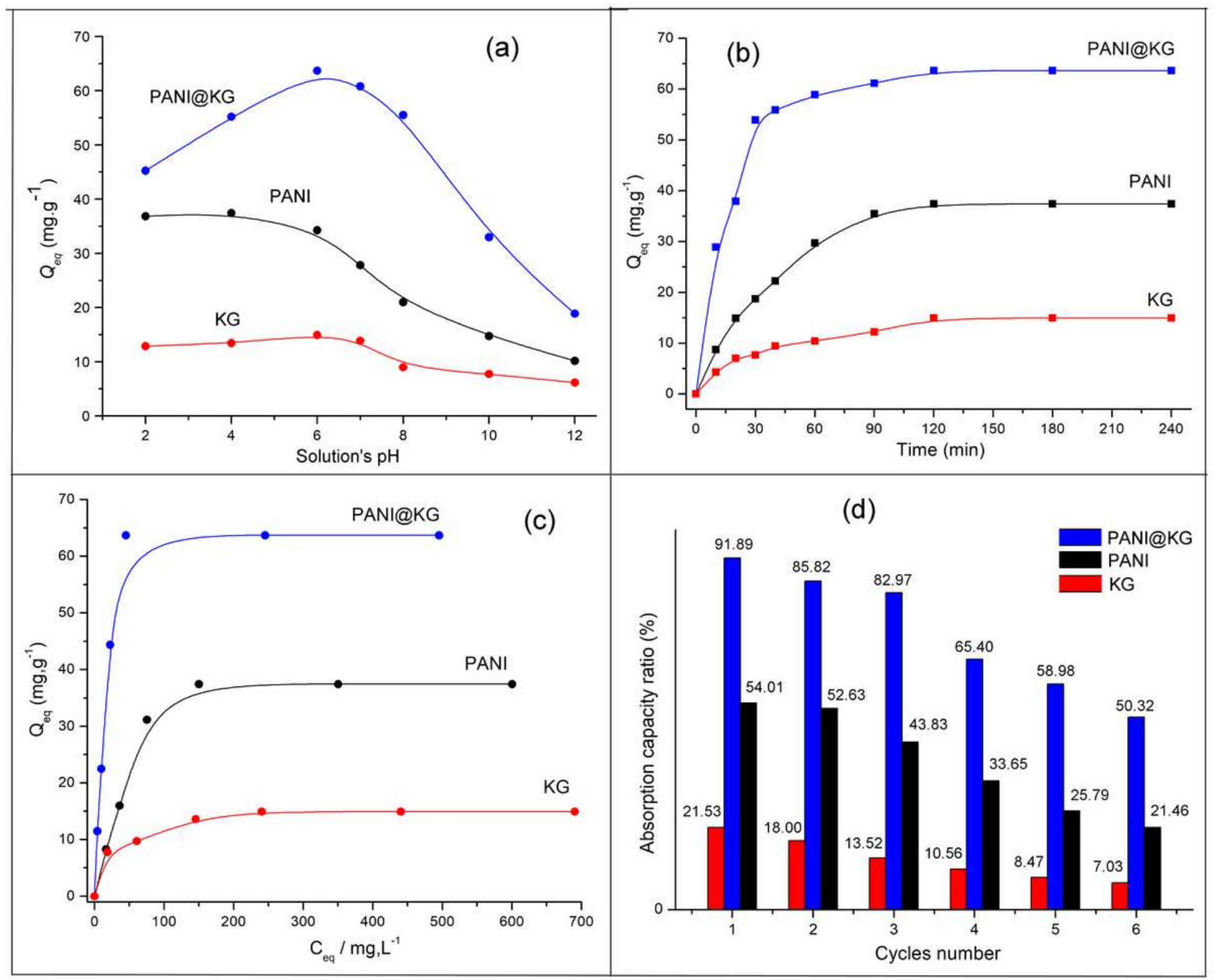

Figure 6

(a) Effect of pHs on the adsorption capacity, (b) Contact Time (C0: 500 mg.L-1; pH: 6.0; T: 298K; adsorbent dose: 1g), (c) Adsorption isotherms (adsorbent dose: 1g; BPA 25 mL; T: 298 K; pH: 6.0) and (d) Adsorbent capacity change and first BPA in consecutive cycles (adsorbents dose: 1g; BPA: 25mL; T: 298K; $\mathrm{pH}$ 6.0). 